CLINICAL STUDY

\title{
Genetic variation at the IGF1 locus shows association with post-stroke outcome and to circulating IGF1
}

\author{
N David Åberg ${ }^{1,4, *}$, Sandra Olsson ${ }^{2,3, *}$, Daniel Åberg ${ }^{1}$, Katarina Jood ${ }^{3}$, Tara M Stanne ${ }^{2}$, Michael Nilsson ${ }^{4,5}$, \\ Christian Blomstrand ${ }^{3}$, Johan Svensson ${ }^{1}$, Jörgen Isgaard ${ }^{1, \dagger}$ and Christina Jern ${ }^{2,3, \dagger}$ \\ ${ }^{1}$ Laboratory of Experimental Endocrinology, Department of Internal Medicine, The Sahlgrenska Academy, Sahlgrenska University Hospital, ${ }^{2}$ Department of \\ Clinical Genetics, ${ }^{3}$ Department of Clinical Neuroscience and Rehabilitation, Institute of Neuroscience and Physiology, The Sahlgrenska Academy and \\ ${ }^{4}$ The Institute of Neuroscience and Physiology, The Sahlgrenska Academy, Center of Brain Repair and Rehabilitation, University of Gothenburg, \\ Blåa Stråket 5, SE-413 45 Gothenburg, Sweden and ${ }^{5}$ Hunter Medical Research Institute, University of Newcastle, Newcastle, New South Wales, Australia
}

(Correspondence should be addressed to N D Åberg at Laboratory of Experimental Endocrinology; Email: david.aberg@medic.gu.se)

*(ND Åberg and S Olsson contributed equally to this work)

†(J Isgaard and C Jern contributed equally to this work)

\begin{abstract}
Objective: In humans, serum IGF1 (s-IGF1) is associated with outcome after ischemic stroke (IS). Therefore variation at the IGF1 locus could also associate with both IS and s-IGF1. We investigated whether genetic variation at the IGF1 locus is associated with i) s-IGF1, ii) IS occurrence, iii) IS severity, and iv) post-stroke outcome.

Design/methods: Patients ( $n=844 ; 66 \%$ males, mean age 56 years) and community controls $(n=668)$ were included from the Sahlgrenska Academy Study on Ischemic Stroke (SAHLSIS). Post-stroke outcome was evaluated with the modified Rankin Scale at 3 and 24 months after index stroke, and baseline stroke severity with the Scandinavian Stroke Scale. s-IGF1 was determined in patients and after random selection in 40 of the controls.

Results: Eleven single nucleotide polymorphisms (SNPs) were selected in the IGF1 gene. In healthy controls the major allele of rs7136446 was associated with higher s-IGF1, whereas in patients no such association was found. No SNP was associated with IS, nor with stroke severity. After multivariate correction for presence of diabetes, smoking, and hypertension, the major allele of rs7136446 was associated with favorable functional outcome 24-months post-stroke (odds ratio 1.46; 95\% CI 1.09-1.96). Conclusion: Variation in rs7136446 of the IGF1 gene associates with post-stroke outcome in relatively young IS patients. Also, rs7136446 associates with s-IGF1 in controls but not in IS, which indicates that IS perturbs a normal genetic impact on s-IGF1 levels.
\end{abstract}

European Journal of Endocrinology 169 759-765

\section{Introduction}

Insulin-like growth factor 1 (IGF1) affects brain plasticity after brain injuries as well as cognition and mood in the healthy brain. In line with this, compounds that affect mood and plasticity after brain injuries also affect local IGF1. Specifically, serotonin reuptake inhibitors, which affects local brain IGF1 levels in experimental animals (1), also improve stroke outcome in humans (2). Furthermore, circulating serum IGF1 (s-IGF1) is associated with better recovery after ischemic stroke (IS) $(3,4)$. Circulating s-IGF1 is regulated by growth hormone from the pituitary, but also by other factors such as age, metabolic state, and possibly physical activity $(5,6)$. Specifically, s-IGF1 is lower in higher ages and in subjects with the metabolic syndrome, whereas physical activity is at least partially associated with higher s-IGF1. These factors act on s-IGF1 via degradation/stability and on de novo synthesis of IGF1 protein. Part of this is determined by primary transcriptional mechanisms in the IGF1 gene locus. Variations at the IGF 1 gene locus include several single nucleotide polymorphisms (SNPs), and a 192 base-pair cytosine-adenine repeat polymorphism (192 bp CA-repeat) in the promoter region. The absence of the 192 bp CA-repeat is associated with lower levels of s-IGF1 (7), an increased risk of IS and a lower longterm survival after IS (8). This variant also shows association with an increased risk of myocardial infarction (MI) and diabetes (7). Another study reported an association between rs2229765 in the IGF1 receptor gene (IGF1R) and IS (9). However, to our knowledge, no other genetic variants in the IGF1 or IGF1R genes have been investigated in relation to IS occurrence or poststroke outcome. The objectives of this study were therefore to investigate whether genetic variation in IGF1 is associated with s-IGF1, IS occurrence, stroke severity, and/or post-stroke outcome. 


\section{Subjects and methods}

The design of Sahlgrenska Academy Study on Ischemic Stroke (SAHLSIS) has been reported elsewhere $(4,10)$. Briefly, patients ( $<70$ years) with first-ever or recurrent acute IS were recruited consecutively at four Stroke Units in western Sweden between 1998 and 2008 $(n=844)$. Caucasian community controls $(n=668)$ from the same geographic area were randomly selected from population registers to match the sex and average age of cases. For the first 600 cases, data on functional outcome (modified Rankin Scale (mRS)) after 3 and 24 months or stroke severity (Scandinavian Stroke Scale (SSS)) acutely were available. From these subjects, s-IGF1 levels in 407 patients and in 40 randomly selected controls were available from a previous study (4). The s-IGF1s of these subjects were analyzed in 2008 in one series of experiments. The frequency of previous hypertension, diabetes mellitus, and smoking was recorded. Participants or next of kin provided written informed consent. This study was approved by the Ethics Committee of the University of Gothenburg. Data and characteristics of each distinct subgroup of samples have been reported previously $(4,10,11)$, and is also compiled in Table 1.

Genotyping was performed using the Golden Gate assay (Illumina, Inc., San Diego, CA, USA) at the SNP\&SEQ Technology platform (www.genotyping.se), with support from Uppsala University and Knut and
Alice Wallenberg Foundation. The genotyping was performed blinded to case/control status. Allele frequencies in the different genotypes are shown in Table 2. The statistical power of the analysis was calculated using the Genetic Power Calculator at http:// pngu.mgh.harvard.edu/ purcell/gpc/ (12).

Eleven SNPs were selected to capture the common variation in IGF1 based on data from the HapMap project on the CEU population (release 23) (13). The linkage disequilibrium (LD) blocks were defined using Haploview 4.1 and the method solid spine of $\mathrm{LD}$ (C) 2003-2006 Broad Institute of MIT and Harvard, MA). Nine of the 11 SNPs in IGF1 were found to be situated in two different LD blocks. The remaining two single SNPs were on either side of these two blocks, making four LD 'blocks' in total (Supplementary Figure 1, see section on supplementary data given at the end of this article). Hence, to correct for multiple testing according to Bonferroni, the crude $P$ values were multiplied by four. The 'Tagger' program in HaploView was used to select this minimal set of tagSNPs, such that all alleles had a minor allele frequency (MAF) $>0.1$ and were correlated at an $r^{2}>0.8$.

Statistical evaluation was performed using SPSS versions 16.0 and 17.0 (SPSS, Inc.). Associations between single SNPs and the various factors were investigated using an additive model. Data on functional outcome was dichotomized (favorable outcome, mRS 0-2 vs unfavorable outcome, mRS 3-6).

Table 1 Baseline characteristics and missing data of SAHLSIS participants in the overall samples, as well as in the subset of subjects with s-IGF1 data. There are more patients with complete genotype data than those with data on outcome as shown. Data on male (sex), presence of diabetes, hypertension, smoking, stroke severity (according to the Scandinavian Stroke Scale (SSS)), stroke outcome after 3 and 24 months (according to the modified Ranking scale (mRS), where mRS $=0-2$ is a favorable outcome) are presented. Data are shown as mean $95 \% \mathrm{Cl}$ and S.D., or number $(n)$ and percentage (\%). Missing data are presented and based on total numbers included in the study. However, data on percentages of 'yes' or 'favorable outcome' are based only on the total numbers of subjects with available data.

\begin{tabular}{|c|c|c|c|c|c|}
\hline & \multicolumn{3}{|c|}{ All subjects } & & \\
\hline & \multirow[b]{2}{*}{ Controls } & \multicolumn{2}{|c|}{ Patients } & \multicolumn{2}{|c|}{ Subjects (s-IGF1) } \\
\hline & & Genotyped & Outcome & Controls & Patients \\
\hline Total $(n)$ & 668 & 844 & 600 & 40 & 407 \\
\hline Age (years; mean \pm s.D. $( \pm 95 \% \mathrm{CI}))$ & $56 \pm 10.4(0.8)$ & $56.3 \pm 10.5(0.7)$ & $56.7 \pm 10.3(0.8)$ & $55.3 \pm 12.6(3.9)$ & $54.9 \pm 10.1(1.0)$ \\
\hline Sex (males; $n(\%))$ & $392(58.7)$ & $5 \overline{54}(65.6)$ & $3 \overline{85}(64.2)$ & $24(60.0)$ & $259(63.6)$ \\
\hline \multicolumn{6}{|l|}{ Diabetes $(n(\%))$} \\
\hline Yes & $33(4.9)$ & $153(18.1)$ & $114(19)$ & $1.0(2.5)$ & $75(18.4)$ \\
\hline Missing & $2(0.3)$ & $0(0)$ & $0(0)$ & $0(0)$ & $0(0)$ \\
\hline \multicolumn{6}{|l|}{ Hypertension ( $n(\%))$} \\
\hline Yes & $230(34.4)$ & $487(57.7)$ & 354 (59) & $10(25)$ & $221(54.3)$ \\
\hline Missing & $1(0.1)$ & $11(1.3)$ & $8(1.3)$ & $0(0)$ & $0(0)$ \\
\hline \multicolumn{6}{|l|}{ Currently smoking ( $n(\%))$} \\
\hline Yes & $131(19.6)$ & $324(38.4)$ & $233(38.8)$ & $11(27.5)$ & $157(38.6)$ \\
\hline Missing & $0(0)$ & $4(0.5)$ & $3(0.5)$ & $0(0)$ & $0(0)$ \\
\hline $\begin{array}{l}\text { Stroke severity (SSS; mean } \pm \text { S.D. } \\
\quad( \pm 95 \% \mathrm{Cl}))\end{array}$ & & & $44.6 \pm 12.1(1.0)$ & & $46.4 \pm 14.1(1.4)$ \\
\hline Missing & & & $14(2.3)$ & & $0(0)$ \\
\hline \multicolumn{6}{|l|}{ Stroke outcome (3 months; $n(\%)$ ) } \\
\hline mRS $0-2$ & & & $438(77.0)$ & & $288(75.2)$ \\
\hline Missing & & & $31(5.2)$ & & $24(5.9)$ \\
\hline \multicolumn{6}{|l|}{ Stroke outcome (24 months; $n(\%)$ ) } \\
\hline mRS $0-2$ & & & $458(77.4)$ & & $309(79.8)$ \\
\hline Missing & & & $8(1.3)$ & & $20(4.9)$ \\
\hline
\end{tabular}


Table 2 Genotype frequencies for IGF1 single nucleotide polymorphisms (SNP) in patients and controls. Descriptive data of the study regarding numbers of subjects with the specific alleles as indicated. Also the number of subjects with missing data is shown.

\begin{tabular}{|c|c|c|c|c|c|c|c|}
\hline \multicolumn{4}{|c|}{ SNP information } & \multicolumn{2}{|c|}{ Controls } & \multicolumn{2}{|c|}{ Patients } \\
\hline SNP no. & SNP name & Location & Genotype & $n$ & $\%^{a}$ & $n$ & $\%^{\mathrm{a}}$ \\
\hline \multirow[t]{4}{*}{1} & rs2162679 & Intron 1 & $\mathrm{~A} / \mathrm{A}$ & 466 & 71.4 & 574 & 72.1 \\
\hline & & & $A / G$ & 168 & 25.7 & 201 & 25.2 \\
\hline & & & $\mathrm{G} / \mathrm{G}$ & 18 & 2.7 & 21 & 2.6 \\
\hline & & & NA & 16 & 2.3 & 48 & 5.6 \\
\hline \multirow[t]{4}{*}{2} & rs12821878 & Intron 2 & $\mathrm{~A} / \mathrm{A}$ & 47 & 7.0 & 44 & 5.2 \\
\hline & & & $A / G$ & 240 & 36.0 & 303 & 36.0 \\
\hline & & & $\mathrm{G} / \mathrm{G}$ & 379 & 56.9 & 493 & 58.6 \\
\hline & & & NA & 2 & 0.2 & 4 & 0.4 \\
\hline \multirow[t]{4}{*}{3} & rs1019731 & Intron 2 & $A / A$ & 18 & 2.7 & 18 & 2.1 \\
\hline & & & $\mathrm{A} / \mathrm{C}$ & 188 & 28.2 & 226 & 26.9 \\
\hline & & & $\mathrm{C} / \mathrm{C}$ & 460 & 69.0 & 596 & 70.9 \\
\hline & & & NA & 2 & 0.2 & 4 & 0.4 \\
\hline \multirow[t]{4}{*}{4} & rs7956547 & Intron 2 & $\mathrm{~A} / \mathrm{A}$ & 374 & 56.2 & 447 & 53.2 \\
\hline & & & $A / G$ & 244 & 36.6 & 334 & 39.7 \\
\hline & & & $\mathrm{G} / \mathrm{G}$ & 47 & 7.0 & 59 & 7.0 \\
\hline & & & NA & 3 & 0.4 & 4 & 0.4 \\
\hline \multirow[t]{4}{*}{5} & rs5742632 & Intron 2 & $\mathrm{~A} / \mathrm{A}$ & 387 & 58.1 & 461 & 54.9 \\
\hline & & & $A / G$ & 232 & 34.8 & 329 & 39.2 \\
\hline & & & $\mathrm{G} / \mathrm{G}$ & 46 & 6.9 & 49 & 5.8 \\
\hline & & & NA & 3 & 0.4 & 5 & 0.5 \\
\hline \multirow[t]{4}{*}{6} & rs9989002 & Intron 2 & $\mathrm{~A} / \mathrm{A}$ & 55 & 8.2 & 73 & 8.7 \\
\hline & & & $\mathrm{A} / \mathrm{G}$ & 244 & 36.6 & 334 & 39.8 \\
\hline & & & $\mathrm{G} / \mathrm{G}$ & 367 & 55.1 & 431 & 51.4 \\
\hline & & & NA & 2 & 0.2 & 6 & 0.7 \\
\hline \multirow[t]{4}{*}{7} & rs7136446 & Intron 2 & $A / A$ & 300 & 45.1 & 344 & 41.0 \\
\hline & & & $A / G$ & 283 & 42.5 & 386 & 46.0 \\
\hline & & & $\mathrm{G} / \mathrm{G}$ & 82 & 12.3 & 109 & 12.9 \\
\hline & & & NA & 3 & 0.4 & 5 & 0.5 \\
\hline \multirow[t]{4}{*}{8} & rs10860865 & Intron 2 & $A / A$ & 46 & 6.9 & 57 & 6.7 \\
\hline & & & $\mathrm{A} / \mathrm{C}$ & 236 & 35.4 & 329 & 39.1 \\
\hline & & & $\mathrm{C} / \mathrm{C}$ & 384 & 57.6 & 454 & 54.0 \\
\hline & & & NA & 2 & 0.2 & 4 & 0.4 \\
\hline \multirow[t]{4}{*}{9} & rs5742671 & Intron 2 & $\mathrm{~A} / \mathrm{A}$ & 22 & 3.3 & 26 & 3.0 \\
\hline & & & $A / G$ & 173 & 25.9 & 246 & 29.2 \\
\hline & & & $\mathrm{G} / \mathrm{G}$ & 471 & 70.7 & 568 & 67.6 \\
\hline & & & NA & 2 & 0.2 & 4 & 0.4 \\
\hline \multirow[t]{4}{*}{10} & rs1520220 & Intron 3 & $\mathrm{C} / \mathrm{C}$ & 464 & 69.6 & 559 & 66.5 \\
\hline & & & $C / G$ & 177 & 26.5 & 249 & 29.6 \\
\hline & & & $\mathrm{G} / \mathrm{G}$ & 25 & 3.7 & 32 & 3.8 \\
\hline & & & NA & 2 & 0.2 & 4 & 0.4 \\
\hline \multirow[t]{4}{*}{11} & rs6214 & Exon 4 & $\mathrm{~A} / \mathrm{A}$ & 101 & 15.1 & 117 & 13.9 \\
\hline & & & $\mathrm{A} / \mathrm{G}$ & 301 & 45.1 & 394 & 46.9 \\
\hline & & & $\mathrm{G} / \mathrm{G}$ & 264 & 39.6 & 329 & 39.1 \\
\hline & & & NA & 2 & 0.2 & 4 & 0.4 \\
\hline
\end{tabular}

${ }^{a}$ Regarding genotype frequencies for each SNP, the percentages are calculated with respect to the total number of genotyped controls or patients (excluding subject with missing data, not available (NA)). For NA the percentages are calculated relative total number of controls or patients.

Logistic regression was used to assess the relative frequencies of the major allele for each SNP in i) patients and controls, ii) patients surviving the IS, and iii) favorable vs unfavorable outcome. Stroke severity and s-IGF1 were evaluated by linear regression. Odds ratios (OR) or linear coefficients $(B)$ and 95\% CIs were with respect to the major allele and age- and sex-corrected. The vascular risk factor confounders of smoking, hypertension, and diabetes were also corrected for in an additional analysis. Assuming a multiplicative genetic model, the ORs that can be detected with $80 \%$ power at a significance level of 5\% are in the range of 1.23-1.37. with $\mathrm{MAF}=0.42-0.11$ of the high risk allele. All genotype distributions were compatible with the Hardy-Weinberg equilibrium ( $P>0.05$, not shown), and the genotyping success rates were $95-100 \%$ (Table 2). The statistical significance level was $P<0.05$. For further details on study design, patient examination, genotyping methods, protein measurements, and statistical analyses please see the Supplementary information, see section on supplementary data given at the end of this article. 


\section{Results}

Baseline characteristics of SAHLSIS are summarized in Table 1. Age and sex distributions were similar in controls and patients, including the group in which s-IGF1 was analyzed. However, hypertension, diabetes, and smoking were more common in patients, as would be expected. Eleven SNPs were selected to capture the common variation in the IGF1 gene based on the CEU population from the HapMap project (Supplementary Figure 1). The genotype frequencies in controls and IS patients are presented in Table 2.

The s-IGF1 levels in SAHLSIS have been previously reported (4) and were used to investigate whether IGF1 SNPs are associated with s-IGF1 levels. In the healthy controls, the major allele of rs7136446 was associated with elevated s-IGF1 (Table 3). However, in IS cases, there were no significant associations between s-IGF1 and any of the IGF1 SNPs either acutely or at 3 months post-stroke (Table 3). Additional correction for smoking, hypertension, and diabetes did not alter the associations (not shown).

To identify possible associations between the IGF1 SNPs and IS, we performed multivariable logistic regression adjusting for age and sex. Occurrence of IS was not associated with any IGF1 SNP (Table 4). Additional correction for smoking, hypertension, and diabetes did not alter the association (not shown).

Elevated s-IGF1 has been shown to associate with enhanced post-stroke recovery. In analogy to that, different IGF1 expression due to genotype variants could be associated with neuroprotective action and reduce acute stroke severity. This was evaluated by linear regression analysis of the SSS with respect to IGF1 SNPs (Table 5). Interestingly, there was a trend for the association of the major allele of rs9989002 (i.e. SNP 6) with less severe IS, i.e. higher SSS scores. Additional correction for smoking, hypertension, and diabetes gave similar associations (not shown).
Association between IGF1 variants and post-stroke outcome was analyzed for each SNP with regard to favorable functional outcome (i.e. $\mathrm{mRS}=0-2$ ) after 3 and 24 months. The major allele of SNP rs7136446 was associated with favorable functional outcome 24 months after IS, after correction for age, sex, smoking, hypertension, and diabetes (i.e. SNP 7, Table 6). However, after Bonferroni adjustment of $P$ values, no SNP showed association with functional outcome after 3 months (Table 6).

Another measure of functional outcome after stroke is survival. When survival 3- and 24-months poststroke was analyzed, no association was detected for any of the SNPs (after Bonferroni's adjustment, $P>0.3$ for all SNPs, not shown).

\section{Discussion}

This is the first study to investigate the genetic variation at the IGF1 locus in relation to IS and s-IGF1 using a tagSNP approach. The main finding was that the SNP rs7136446 showed association to functional outcome 24 months after index stroke. In healthy controls, the major allele of the same SNP was associated with higher levels of s-IGF1. In contrast, in IS patients, rs7136446 was not associated with s-IGF1. For the major allele of rs9989002, there was a trend toward an association with less initial stroke severity. None of the SNPs analyzed were associated with occurrence of IS compared with controls.

Here, we present the novel data that functional independence (mRS 0-2) 24 months after index stroke is associated with the major allele of rs7136446. A similar trend was observed 3 months after index stroke, however this did not withstand correction for multiple testing (crude, $P=0.029$ and adjusted, $P=0.116$ ). If this SNP is associated with post-stroke recovery, one would expect the association to increase with time after stroke. Indeed, this is what we observed.

Table 3 Association between IGF1 SNPs and serum IGF1 levels in patients and controls in SAHLSIS. Linear coefficients $(B)$ and $95 \%$ Cls are calculated with respect to the major allele corrected for age and sex. The $B$ value is expressed so that a positive value represents elevated s-IGF1 in the major allele.

\begin{tabular}{|c|c|c|c|c|c|c|c|c|c|}
\hline \multirow{2}{*}{$\begin{array}{l}\text { SNP } \\
\text { no. }\end{array}$} & \multirow{2}{*}{$\begin{array}{c}\text { Acute patients } \\
\quad(n=384) \\
B( \pm 95 \% \mathrm{Cl})\end{array}$} & \multicolumn{2}{|c|}{$P$ values } & \multirow{2}{*}{$\begin{array}{c}3 \text { months patients } \\
(n=369) \\
B( \pm 95 \% \mathrm{Cl})\end{array}$} & \multicolumn{2}{|c|}{$P$ values } & \multirow{2}{*}{$\begin{array}{l}\text { Healthy controls } \\
\qquad \begin{array}{c}(n=40) \\
B( \pm 95 \% \mathrm{Cl})\end{array}\end{array}$} & \multicolumn{2}{|c|}{$P$ values } \\
\hline & & Crude & Adjusted & & Crude & Adjusted & & Crude & Adjusted \\
\hline & $7.5(-4.4$ to 19.4$)$ & 0.21 & 0.5 & $2.1(-8.6$ to 12.8$)$ & $>0.5$ & 0.5 & $-3.2(-27.2$ to 20.8$)$ & $>0.5$ & $>0$. \\
\hline & & 0 & & & & & -19 & & \\
\hline 3 & $-5.7(-17.7$ to 6.4$)$ & 0.356 & & $1.6(-12.3$ to 9.0$)$ & $>0.5$ & & $-8.6(-31.4$ to 14.3$)$ & 0.453 & $>0.5$ \\
\hline 4 & $5.0(-4.8$ to 14.8$)$ & 0.316 & $>0.5$ & $1.9(-7.2$ to 10.9$)$ & $>0.5$ & $>0.5$ & $5.1(-14.1$ to 24.2$)$ & $>0.5$ & $>0.5$ \\
\hline 5 & $-0.2(-10.6$ to 10.1$)$ & $>0.5$ & $>0.5$ & $-0.8(-10.4$ to 8.8$)$ & $>0.5$ & $>0.5$ & $4.7(-14.8$ to 24.2$)$ & $>0.5$ & $>0.5$ \\
\hline 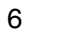 & $-1.4(-10$ & $>0.5$ & & $-4.7 i$ & 0.287 & $>0$ & $-0.5 i-$ & $>0.5$ & $>0.5$ \\
\hline 7 & $-4.4(-13.3$ to 4.4$)$ & 0.325 & $>0.5$ & $-5.4(-1)$ & 0.197 & $>0.5$ & $19.3(5$. & 0.009 & 0.034 \\
\hline 8 & $-4.3(-14.0$ to 5.5$)$ & 0.392 & $>0.5$ & $-6.7(-15.6$ to 2.2$)$ & 0.137 & $>0.5$ & 9.1 ( -10.9 to 29.2$)$ & 0.361 & $>0.5$ \\
\hline 9 & $-3.5(-15.2$ to 8.3$)$ & $>0.5$ & $>0.5$ & $-5.5(-16.4$ to 5.3$)$ & 0.314 & $>0.5$ & $9.7(-11.3$ to 30.8$)$ & 0.354 & $>0.5$ \\
\hline 10 & $-6(-17.1$ to 5.1$)$ & 0.29 & $>0.5$ & $-7.0(-17.2$ to 3.2$)$ & 0.179 & $>0.5$ & $5.0(-22.9$ to 32.9$)$ & $>0.5$ & $>0.5$ \\
\hline 11 & $2.3(-6.9$ to 11.5$)$ & $>0.5$ & $>0.5$ & $3.7(-4.5$ to 12.0$)$ & 0.37 & $>0.5$ & $14.2(-1.5$ to 30.0$)$ & 0.076 & $>0.5$ \\
\hline
\end{tabular}

Crude $P$ values are adjusted for multiple comparisons according to Bonferroni as shown. 
Table 4 Minor allele frequencies (MAF) for IGF1 SNPs in controls and patients in SAHLSIS, as well as odds ratios (ORs) for the association between the IGF1 SNPs and ischemic stroke. MAF are shown in the analyses with logistic regression. ORs and $95 \% \mathrm{Cls}$ are calculated with respect to the major allele corrected for age and sex. For IS control/patient comparisons, an OR $>1$ represents an increased frequency of the major allele in the controls (i.e. associates with protection against IS).

\begin{tabular}{lccccc}
\hline & & & & \multicolumn{2}{c}{$\boldsymbol{P}$ values } \\
\cline { 5 - 6 } SNP no. & MAF $(\%)$ control & MAF $(\%)$ patient & OR $( \pm \mathbf{9 5} \% \mathbf{C l})$ & Crude & Adjusted \\
\hline 1 & 15.6 & 15.3 & $1.02(0.83-1.25)$ & $>0.5$ & $>0.5$ \\
2 & 25.1 & 23.3 & $1.11(0.94-1.31)$ & 0.233 & $>0.5$ \\
3 & 16.8 & 15.6 & $1.09(0.9-1.33)$ & 0.387 & $>0.5$ \\
4 & 25.4 & 26.9 & $0.92(0.78-1.09)$ & 0.326 & $>0.5$ \\
5 & 24.4 & 25.4 & $0.94(0.80-1.11)$ & 0.466 & $>0.5$ \\
6 & 26.6 & 28.6 & $0.90(0.77-1.05)$ & 0.181 & $>0.5$ \\
7 & 33.6 & 36.0 & $0.90(0.77-1.05)$ & 0.168 & $>0.5$ \\
8 & 24.6 & 26.4 & $0.91(0.77-1.07)$ & 0.237 & $>0.5$ \\
9 & 16.3 & 17.7 & $0.89(0.74-1.08)$ & 0.251 & $>0.5$ \\
10 & 17.0 & 18.6 & $0.90(0.75-1.08)$ & 0.253 & $>0.5$ \\
11 & 37.8 & 37.4 & $1.01(0.87-1.18)$ & $>0.5$ & $>0.5$ \\
\hline
\end{tabular}

Both crude and $P$ values adjusted for multiple comparisons according to Bonferroni are shown.

The magnitude of association is moderate (OR 1.5), but still this SNP is probably of potential significance in relation with IS because the same SNP is associated with endogenous s-IGF1. Statistical correction for the confounding covariates cannot adjust for the presence of a specific SNP which has been presented life-long. However, covariate correction can be used to test whether an association is mediated by the confounders. If vascular diseases were to mediate the effect of rs713446 on outcome, the association would be weaker after correction and vice versa. Therefore, the increased strength of association between rs713446 and outcome after correction for vascular risk factors indicates an association that is primarily independent of vascular confounders.

Previously, it was shown that another measure of outcome, namely survival, is affected by genetic variation in IGF1. Specifically, increased death rates after IS was reported in non-carriers of the $192 \mathrm{bp}$ CA-repeat (8). We did not find any statistically significant associations between any SNP and survival. However, in contrast to the aforementioned study, SAHLSIS is a study of relatively young stroke sufferers (mean age 56 years). Therefore, the number of deceased patients after 3 and 24 months is relatively low (1.2 and $4.1 \%$ respectively). Thus, the lack of association may simply reflect an overall lack of power regarding survival in this analysis.

Higher s-IGF1 concentrations were associated with the major allele of rs7136446 in healthy controls in this study. This is opposite to what was reported in a study that included only healthy, premenopausal female participants, wherein the major alleles of rs7136446 and rs9989002, both analyzed in our study, were associated with slightly (5-7\%) lower s-IGF1 levels (14). Verheus et al. did not, however, correct for multiple testing in the analysis of 16 SNPs, and also the found differences in s-IGF1 were quite small in magnitude.
Interestingly, the major allele of rs7136446 has recently been associated with maximal muscle force production in 148 Finnish males (15). One could speculate that patients with higher maximal muscle force may recover muscle strength faster, and thus gain better functional independence. This would be compatible with our results, but of course primary neuronal mechanisms could also account for the association to outcome.

In control subjects, circulating s-IGF1 was $37 \%$ higher (not shown) in the most common genotype than in the least common genotype. However, this association was not present at all in the patients. Although the power to detect differences in the healthy control group was lower $(n=40)$ than that in patients $(n=407)$, the associations appear genuine as we corrected for multiple comparisons (Table 3). As

Table 5 Association between IGF1 SNPs and baseline stroke severity as measured by the Scandinavian Stroke Scale (SSS). Linear coefficients $(B)$ and $95 \%$ Cls are calculated with respect to the major allele corrected for age and sex. For stroke severity the $B$ value is expressed so that a positive value represents less severe IS in the major allele.

\begin{tabular}{|c|c|c|c|}
\hline \multicolumn{2}{|c|}{ Stroke severity } & \multirow{2}{*}{\multicolumn{2}{|c|}{$P$ values }} \\
\hline & SSS & & \\
\hline SNP no. & $B( \pm 95 \% \mathrm{Cl})$ & Crude & Adjusted \\
\hline 1 & $1.7(-0.2$ to 3.7$)$ & 0.084 & 0.336 \\
\hline 2 & $1.2(-0.4$ to 2.9$)$ & 0.137 & $>0.5$ \\
\hline 3 & $1.4(-0.5$ to 3.3$)$ & 0.151 & $>0.5$ \\
\hline 4 & $0.8(-0.8$ to 2.4$)$ & 0.347 & $>0.5$ \\
\hline 5 & $0.4(-1.2$ to 2.1$)$ & $>0.5$ & $>0.5$ \\
\hline 6 & $1.8(0.3$ to 3.3$)$ & 0.022 & 0.086 \\
\hline 7 & $1.2(-0.2$ to 2.7$)$ & 0.098 & 0.391 \\
\hline 8 & $-1.4(-3.0$ to 0.2$)$ & 0.077 & 0.309 \\
\hline 9 & $-0.8(-2.7$ to 1.1$)$ & 0.4 & $>0.5$ \\
\hline 10 & $1.0(-0.9$ to 2.8$)$ & 0.303 & $>0.5$ \\
\hline 11 & $-0.3(-1.7$ to 1.2$)$ & $>0.5$ & $>0.5$ \\
\hline
\end{tabular}

Crude $P$ values are adjusted for multiple comparisons according to Bonferroni as shown. 
Table 6 Association between IGF1 SNPs and favorable post-stroke outcome at 3 and 24 months after index stroke in SAHLSIS. Minor allele frequencies (MAF) are shown for mRS 0-2 and 3-6. Odds ratios (OR) and 95\% Cls are calculated with respect to the major allele corrected for age and sex. An OR $>1$ represents the OR of having a favorable outcome (i.e. mRS 0-2) with respect to the major allele.

\begin{tabular}{|c|c|c|c|c|c|c|c|c|c|c|}
\hline \multirow{3}{*}{$\begin{array}{l}\text { SNP } \\
\text { no. }\end{array}$} & \multicolumn{5}{|c|}{ mRS 3 months } & \multicolumn{5}{|c|}{ mRS 24 months } \\
\hline & \multicolumn{2}{|c|}{ MAF (\%) } & \multirow[b]{2}{*}{ OR $( \pm 95 \% \mathrm{Cl})$} & \multicolumn{2}{|c|}{$P$ values } & \multicolumn{2}{|c|}{ MAF (\%) } & \multirow[b]{2}{*}{ OR $( \pm 95 \% \mathrm{Cl})$} & \multicolumn{2}{|c|}{$P$ values } \\
\hline & mRS 0-2 & mRS 3-6 & & Crude & Adjusted & mRS 0-2 & mRS 3-6 & & Crude & Adjusted \\
\hline 1 & 14.7 & 16.8 & $1.19(0.81-1.75)$ & 0.368 & $>0.5$ & 15.1 & 15.6 & $1.06(0.72-1.56)$ & $>0.5$ & $>0.5$ \\
\hline 2 & 22.6 & 27.9 & $1.33(0.97-1.83)$ & 0.078 & 0.312 & 22.9 & 25.4 & $1.14(0.83-1.58)$ & 0.417 & $>0.5$ \\
\hline 3 & 15.1 & 17.6 & $1.22(0.84-1.77)$ & 0.295 & $>0.5$ & 14.6 & 18.7 & $1.35(0.94-1.94)$ & 0.107 & 0.427 \\
\hline 4 & 26.3 & 27.9 & $1.08(1.48-0.79)$ & $>0.5$ & $>0.5$ & 26.4 & 27.2 & $1.05(0.77-1.44)$ & $>0.5$ & $>0.5$ \\
\hline 5 & 24.3 & 24.8 & $1.02(0.73-1.42)$ & $>0.5$ & $>0.5$ & 25.2 & 23.3 & $0.91(0.65-1.27)$ & $>0.5$ & $>0.5$ \\
\hline 6 & 26.4 & 32.1 & $1.31(1.77-0.97)$ & 0.076 & 0.304 & 27.1 & 29.7 & $1.15(0.85-1.55)$ & $>0.5$ & $>0.5$ \\
\hline 7 & 32.8 & 40.1 & $1.38(1.03-1.85)$ & 0.029 & 0.116 & 33.0 & 41.0 & $1.42(1.07-1.9)$ & 0.017 & $0.067^{a}$ \\
\hline 8 & 24.5 & 28.2 & $1.22(0.89-1.67)$ & 0.217 & $>0.5$ & 25.2 & 26.1 & $1.05(0.77-1.44)$ & $>0.5$ & $>0.5$ \\
\hline 9 & 16.4 & 18.7 & $1.18(0.81-1.71)$ & 0.387 & $>0.5$ & 17.0 & 17.2 & $1.01(0.7-1.47)$ & $>0.5$ & $>0.5$ \\
\hline 10 & 17.0 & 19.5 & $1.18(0.83-1.68)$ & 0.351 & $>0.5$ & 17.4 & 17.9 & $1.03(0.72-1.47)$ & $>0.5$ & $>0.5$ \\
\hline 11 & 38.3 & 34.7 & $0.85(0.63-1.14)$ & 0.284 & $>0.5$ & 38 & 37.7 & $0.99(0.74-1.32)$ & $>0.5$ & $>0.5$ \\
\hline
\end{tabular}

Crude $P$ values are adjusted for multiple comparisons according to Bonferroni as shown.

${ }^{a}$ After additional correction for confounders (smoking, hypertension, and diabetes) and Bonferroni's adjustment, this analysis reached statistical significance $(P=0.049$, OR $1.46,95 \% \mathrm{Cl} 1.09-1.96) . P<0.05$ values after Bonferroni adjustment are in bold.

s-IGF1 is regulated by environmental factors (5), this may indicate that IS per se strongly affects the normal impact of this SNP on s-IGF1. Indeed, after experimental IS, local IGF1 in the brain is upregulated (16). As the blood-brain barrier is often injured after IS a local increase of IGF1 may disseminate into the circulation. In this way IS per se may be such a strong regulator of IGF1 synthesis, that a normal endogenous association between rs7136446 and s-IGF1 disappears.

While specific SNPs were associated with either stroke severity, stroke outcome, or s-IGF1, we did not observe any statistically significant associations between IS patients and controls in terms of frequency of the IGF1 SNPs variations. This analysis is considered to be an indirect assessment of the relative risk of being afflicted by IS comparing genotypes of IS patients and healthy controls. This is in contrast to an earlier study which reported an association between noncarriers of a 192 bp CA-repeat in the IGF1 promoter and risk of IS (8). Similarly, the absence of the CA-repeat has been associated with MI, as well as with lower levels of s-IGF1 (7). The tagSNP rs7965399 is in LD with the 192 bp CA-repeat (17); however it is uncommon in subjects of Caucasian origin (MAF 0.02, HapMap). Therefore, it did not meet the tagSNP selection criteria and was not included in this study. Two other SNPs, rs7956547 and rs2162679, have been reported to associate with MI in a Japanese study of 320 patients (18), but these two SNPs did not display significant associations with IS in this study. Notably, the associations with MI were not corrected for multiple testing of six SNPs, and are therefore uncertain.

Methodological and statistical strengths of this study include consecutive recruitment of well-characterized and relatively young IS cases and population-based controls. This, in combination with the very high hospitalization rate $(84-95 \%)$ for stroke (especially $<70$ years) in Sweden (19), makes selection bias unlikely. In addition, few patients were lost to the follow-up. Weaknesses include the relatively small sample size and lack of replication in another geographic area. Although the associations we report are relatively weak, it should be noted that strict correction for multiple testing was made, which is in contrast to earlier studies of genetic variation.

In conclusion, our study indicates that the major allele of rs7136446 is associated with favorable functional outcome 24-months post-stroke and with s-IGF1 in healthy controls but not in patients. The results point toward a role for IGF1 in post-stroke outcome but not for stroke risk, but this needs validation in independent samples.

\section{Supplementary data}

This is linked to the online version of the paper at http://dx.doi.org/ 10.1530/EJE-13-0486.

\section{Declaration of interest}

The authors declare that there is no conflict of interest that could be perceived as prejudicing the impartiality of the research reported.

\section{Funding}

This study was supported by the Swedish Medical Society (Svenska Läkaresällskapet), grants from the Swedish Government (ALFGBG11206, ALFGBG-147771, and ALFGBG-148861), the Swedish Research Council (K2011-65X-14605-09-6), the Swedish Heart Lung Foundation (20100256), the Swedish Stroke Association, the Göteborg Foundation for Neurological Research, and the Yngve Land, Rune and Ulla Amlöv, Edit Jacobson, Magnus Bergvall, Emelle, Lars Hierta, and John and Brit Wennerström foundations. 


\section{Author contribution statement}

N D Åberg and S Olsson planned, designed, performed, analyzed, and wrote the study. D Åberg, M Nilsson, and C Blomstrand planned and wrote the study. K Jood analyzed and wrote the study. T M Stanne and J Svensson wrote the study. J Isgaard and C Jern planned, designed, and wrote the study. All authors contributed to and have approved the final manuscript. N D Åberg and S Olsson contributed equally and are joint first authors, and J Isgaard and C Jern are in joint senior position.

\section{References}

1 Grunbaum-Novak N, Taler M, Gil-Ad I, Weizman A, Cohen H \& Weizman R. Relationship between antidepressants and IGF-1 system in the brain: possible role in cognition. European Neuropsychopharmacology $2008 \mathbf{1 8}$ 431-438. (doi:10.1016/ j.euroneuro.2007.08.004)

2 Chollet F, Tardy J, Albucher JF, Thalamas C, Berard E, Lamy C, Bejot Y, Deltour S, Jaillard A, Niclot P et al. Fluoxetine for motor recovery after acute ischaemic stroke (FLAME): a randomised placebo-controlled trial. Lancet Neurology $2011 \quad 10$ 123-130. (doi:10.1016/S1474-4422(10)70314-8)

3 Bondanelli M, Ambrosio MR, Onofri A, Bergonzoni A, Lavezzi S, Zatelli MC, Valle D, Basaglia N \& degli Uberti EC. Predictive value of circulating insulin-like growth factor I levels in ischemic stroke outcome. Journal of Clinical Endocrinology and Metabolism 200691 3928-3934. (doi:10.1210/jc.2006-1040)

4 Åberg D, Jood K, Blomstrand C, Jern C, Nilsson M, Isgaard J \& Åberg ND. Serum IGF-I levels correlate to improvement of functional outcome after ischemic stroke. Journal of Clinical Endocrinology and Metabolism 201196 E1055-E1064. (doi:10.1210/jc.20102802)

5 Parekh N, Roberts CB, Vadiveloo M, Puvananayagam T, Albu JB \& Lu-Yao GL. Lifestyle, anthropometric, and obesity-related physiologic determinants of insulin-like growth factor-1 in the Third National Health and Nutrition Examination Survey (1988-1994). Annals of Epidemiology $2010 \quad 20 \quad$ 182-193. (doi:10.1016/ j.annepidem.2009.11.008)

6 Landin-Wilhelmsen K, Wilhelmsen L, Lappas G, Rosén T, Lindstedt G, Lundberg PA \& Bengtsson BA. Serum insulin-like growth factor $I$ in a random population sample of men and women: relation to age, sex, smoking habits, coffee consumption and physical activity, blood pressure and concentrations of plasma lipids, fibrinogen, parathyroid hormone and osteocalcin. Clinical Endocrinology 199441 351-357. (doi:10.1111/j.1365-2265. 1994.tb02556.x)

7 Vaessen N, Heutink P, Janssen JA, Witteman JC, Testers L, Hofman A, Lamberts SW, Oostra BA, Pols HA \& van Duijn CM A polymorphism in the gene for IGF-I: functional properties and risk for type 2 diabetes and myocardial infarction. Diabetes 2001 50 637-642. (doi:10.2337/diabetes.50.3.637)

8 van Rijn MJ, Slooter AJ, Bos MJ, Catarino CF, Koudstaal PJ, Hofman A, Breteler MM \& van Duijn CM. Insulin-like growth factor I promoter polymorphism, risk of stroke, and survival after stroke: the Rotterdam study. Journal of Neurology, Neurosurgery, and Psychiatry 200677 24-27. (doi:10.1136/jnnp.2005.067447)
9 Cheng J, Liu J, Li X, Peng J, Han S, Zhang R, Xu Y \& Nie S. Insulinlike growth factor-1 receptor polymorphism and ischemic stroke: a case-control study in Chinese population. Acta Neurologica Scandinavica 2008118 333-338. (doi:10.1111/j.1600-0404. 2008.01040.x)

10 Jood K, Ladenvall C, Rosengren A, Blomstrand C \& Jern C. Family history in ischemic stroke before 70 years of age: the Sahlgrenska Academy Study on Ischemic Stroke. Stroke 200536 1383-1387. (doi:10.1161/01.STR.0000169944.46025.09)

11 Olsson S, Jood K, Blomstrand C \& Jern C. Genetic variation on chromosome 9p21 shows association with the ischaemic stroke subtype large-vessel disease in a Swedish sample aged $<=70$. European Journal of Neurology 201118 365-367. (doi:10.1111/ j.1468-1331.2010.03096.x)

12 Purcell S, Cherny SS \& Sham PC. Genetic Power Calculator: design of linkage and association genetic mapping studies of complex traits. Bioinformatics 200319 149-150. (doi:10.1093/bioinformatics/19.1.149)

13 International HapMap Consortium. The International HapMap Project. Nature 2003426 789-796. (doi:10.1038/nature02168)

14 Verheus M, McKay JD, Kaaks R, Canzian F, Biessy C, Johansson M, Grobbee DE, Peeters PH \& van Gils CH. Common genetic variation in the IGF-1 gene, serum IGF-I levels and breast density. Breast Cancer Research and Treatment 2008112 109-122. (doi:10.1007/ s10549-007-9827-x)

15 Huuskonen A, Lappalainen J, Oksala N, Santtila M, Häkkinen K, Kyröläinen H \& Atalay M. Common genetic variation in the IGF1 associates with maximal force output. Medicine and Science in Sports and Exercise 201143 2368-2374. (doi:10.1249/MSS. 0b013e3182220179)

16 Beilharz EJ, Russo VC, Butler G, Baker NL, Connor B, Sirimanne ES, Dragunow M, Werther GA, Gluckman PD, Williams CE et al. Co-ordinated and cellular specific induction of the components of the IGF/IGFBP axis in the rat brain following hypoxic-ischemic injury. Brain Research. Molecular Brain Research $1998 \mathbf{5 9}$ 119-134. (doi:10.1016/S0169-328X(98)00122-3)

17 Cheng I, Stram DO, Penney KL, Pike M, Le Marchand L, Kolonel LN, Hirschhorn J, Altshuler D, Henderson BE \& Freedman ML. Common genetic variation in IGF1 and prostate cancer risk in the Multiethnic Cohort. Journal of the National Cancer Institute 200698 123-134. (doi:10.1093/jnci/ djj013)

18 Aoi N, Nakayama T, Soma M, Kosuge K, Haketa A, Sato M, Sato N, Asai $S$ \& Matsumoto K. Association of the insulin-like growth factor1 gene with myocardial infarction in Japanese subjects. Hereditas 2010147 215-224. (doi:10.1111/j.1601-5223.2010. 02174.x)

19 Hallström B, Jönsson AC, Nerbrand C, Petersen B, Norrving B \& Lindgren A. Lund Stroke Register: hospitalization pattern and yield of different screening methods for first-ever stroke. Acta Neurologica Scandinavica 2007115 49-54. (doi:10.1111/j.16000404.2006.00738.x)

Received 11 June 2013

Revised version received 27 August 2013

Accepted 4 September 2013 